\title{
Fuga como estratégia: notas sobre sexualidade, parentesco e emoções entre pessoas mbya
}

Elizabeth Pissolato

Universidade Federal de Juiz de Fora, Juiz de Fora, Minas Gerais, Brasil

Dol 10.11606/issn.2316-9133.v24i24p412-426

resumo No presente texto, focalizo a fuga como estratégia utilizada com frequência por mulheres e homens mbya na atualização de vínculos sexuais-afetivos. Fugir (-java) de um relacionamento ou fugir com um parceiro ou parceira com quem se quer iniciar um relacionamento constituem, conforme sugere a análise, modos de agenciamento sexual e de exercício de autonomia pessoal articulados com o manejo das emoçóes e o aspecto multilocal do parentesco mbya. $\mathrm{O}$ artigo apresenta essas conexóes para futuros desenvolvimentos e discute as possibilidades de produção de parentesco considerando a prática da fuga.

palavras-chave: Mbya; Sexualidade; Emoçóes; Parentesco; Fuga.

Escaping as a strategy: notes on sexuality, kinship and emotions among Mbya people

abstract In this article we focus on escape as a strategy often used by Mbya women and men to refit sexual-affective bonds. As the paper suggests, to escape from (-java) a relationship and to escape with a partner with whom one wishes to start a new relationship entails modes of sexual agency and exercise of personal autonomy articulated with the management of emotion and the multisite features of Mbya kinship. The article presents these connections for further academic developments and discusses the possibilities of kinship production considering the practice of escape.

keywords: Mbya; Sexuality; Emotions; Kinship; Escape. 


\section{Aproximações: tema e contexto}

Inicio este artigo mencionando o comentário de uma mulher, próxima de seus 25 anos e mãe de três filhos à época em que eu desenvolvia minha pesquisa de campo para o doutorado e vivia na aldeia de Parati Mirim. ${ }^{1}$ Conversávamos sobre casamento, e ela dizia, contrastando sua própria situação com a de uma de suas irmãs, que há mulheres mbya que "casam com quem querem" e há também aquelas que não o fazem, casando-se com quem seus pais desejam ou mantendo-se casadas com quem não desejam por temer não dar conta do sustento dos filhos sem a colaboração do marido. No primeiro caso, que corresponde à trajetória de muitas mulheres mbya adultas, estas teriam se casado por diversas vezes e vivido em diferentes aldeias. E ainda, em várias ocasióes, teriam lançado mão de um recurso frequentemente utilizado por homens e mulheres para pôr fim a uma uniáo conjugal começando outra: a fuga - sem aviso aos parentes ou afins que são deixados para trás - rumo a outra aldeia.

Neste texto, pretendo estabelecer algumas conexóes entre essa prática, a de fugir (-java), e o controle sobre a própria atividade sexual com dimensóes do parentesco e da socialidade mbya. Antes de dar início a esse exercício, contudo, gostaria de fazer duas breves observaçóes em torno da sexualidade, se cabe aplicar o conceito no contexto em questão.

A primeira delas diz respeito ao que já foi observado por colegas antropólogas que desenvolvem pesquisas com povos indígenas sul-americanos (ver LEA e BELAUNDE neste volume): não caberia tratar de sexualidade ou sexualidades indígenas considerando-a(s) a partir da perspectiva ocidental do sujeito ou de uma "ciência do sujeito [que gravita] em torno da questão do sexo" (FOUCAULT, 1980). Longe de remeter ao sujeito ou a seu corpo como fonte de inquietaçáo e cuidado, sexualidade ou sexo, na experiência de povos indígenas sul-americanos, parece "[fazer] parte de conceber e constituir (ou não) as relaçôes sociais com seres marcados pela alteridade" (McCALLUM, 2010, p. 53), sejam eles humanos, animais, espíritos. De outra parte, tal consideração não deve excluir, me parece, uma reflexão sobre a economia do prazer, ainda que não seja fácil, igualmente, definir imediatamente prazer.

De toda maneira, e aqui vai a segunda observação, minha experiência de convívio e pesquisa com pessoas mbya não permitiria tratar ou sequer mapear sistematicamente o que definiríamos como o domínio das práticas sexuais e do exercício da sexualidade. Por exemplo, eu não saberia situar com clareza práticas sexuais entre pessoas do mesmo sexo, como as que vêm sendo descritas e analisadas em diferentes contextos indígenas, inclusive na experiência de pessoas guarani, ñandeva e kaiowá (CANCELA; SILVEIRA; MACHADO, 2010). ${ }^{2}$ 
Nos parágrafos seguintes, situo de modo bastante geral o sexo e a sexualidade no contexto da vida nas aldeias mbya que frequentei, observando alguns aspectos de seu tratamento. Minhas impressōes se construíram principalmente na experiência de conversas nos pátios ou interior das casas que frequentava, e ao acompanhar processos de uniáo e rupturas entre mulheres e homens próximos a mim, processos atuais ou narrados e comentados, que trazem à tona temas como a atração sexual, o ciúme, a produçáo de crianças.

Meu intuito aqui não é chegar a qualquer padrão geral de comportamento sexual ou à definiçáo de uma "cultura sexual" (GREGOR, 1985); interessa-me antes uma aproximaçáo a afetos e questóes que se conectam à matéria.

Sexo e casamento são temas de interesse forte e geral das pessoas mbya. O mapa local e também multilocal - até onde as notícias veiculadas pelo trânsito de pessoas permite - dos vínculos sexuais-afetivos é constantemente atualizado nas conversas, e o "casar" (-menda), que é o termo usado na referência a estas unióes, sejam as mais duradouras ou as que acabaram de se consumar aos olhos dos outros - é um tema-chave da movimentação de pessoas entre as aldeias. A afirmaçáo vale tanto para o contexto de passeios ou visitas a outras áreas, feitos por moças e rapazes geralmente a partir da época em que se iniciam na vida sexual, quanto para os eventos de abandono de parceiros(as) em unióes estabelecidas e de fugas para "casar com outro(a)" (-menda amboa'e).

A atividade sexual pode ter início muito cedo, e o interesse para o envolvimento sexual de cada jovem, mulher ou homem, é um fator decisivo. Como me disse Lídia uma vez, em Parati Mirim, há moças que "gostam de namorar" desde cedo, enquanto outras "não ligam". A despeito de ouvirmos constantemente, nos discursos cerimoniais dos mais velhos, conselhos para que moças e rapazes não se "casem cedo", na prática há moças que iniciam sua atividade sexual mesmo antes de menstruarem, não havendo mecanismos - ao menos eficientes - de controle sobre a atividade sexual dos jovens. Isto a despeito de algum grau de vigilância que tende a existir. Como noutras matérias, pais e mães podem exercer influência sobre filhos e filhas - algumas vezes, mesmo "dar" em casamento filhas, como contam algumas mulheres -, mas não há quem possa efetivamente se contrapor às escolhas que moças e rapazes venham a fazer. Como veremos, a autonomia para o deslocamento entre aldeias assume aqui uma importância especial.

Ao que parece, portanto, a vida sexual nas aldeias mbya implica, de um lado, escolhas sexuais pessoais às quais não cabe contraposição, desde que alcançado um grau mínimo de autonomia pela pessoa em questáo; de outro lado, vigilância e interesse pelas escolhas atualizadas por homens e mulheres no âmbito local e extralocal. 
Tema privilegiado nas conversas em que se "fala dos outros", o sexo é também aqui, como entre muitos povos sul-americanos, matéria para humor, provocando risos com piadas picantes e brincadeiras feitas entre homens e mulheres não parentes nos pátios. Por outro lado, não deixa de ser objeto de discrição quando se trata da atividade sexual de um casal. Assim, é comum que estes procurem meios de manter-se longe dos olhares alheios, seja escolhendo as trilhas na mata para fazer sexo ou colocando cortinas de tecido ao redor de sua cama.

Como veremos adiante, as práticas e escolhas sexuais estão no centro da socialidade mbya. E, se trataremos neste artigo fundamentalmente de suas implicações no âmbito do parentesco e afinidade entre pessoas mbya, é preciso dizer que estas colocam questôes para além da humanidade mbya stricto sensu. O envolvimento sexual está também no centro da socialidade que compreende relações com outras gentes. Ou seja, é um tema central da relaçáo com jurua (brancos) ${ }^{3}$ e também com animais, aqui especialmente quando focalizamos o processo dito -jepota, de transformaçáo animal, que ameaça moças e rapazes na puberdade. ${ }^{4}$ Náo trataremos desses contextos no presente artigo, mas servem-nos aqui para uma observação geral sobre a ambiguidade presente na conjunção sexual. Altamente desejável, o sexo traz consigo uma carga de risco de transformação, que, no limite, pode levar à perda da humanidade (Mbya). No caso do -jepota, pode-se virar onça ou outro bicho; no caso de relação com jurua, pode levar a doença e morte. Mais adiante veremos, no comentário sobre a feitiçaria, que a mesma ambiguidade está presente no sexo e casamento entre pessoas mbya.

\section{Adultério e partida}

Começo meu comentário com o tema do adultério e o mito fundador guarani, que é referido normalmente nas aldeias mbya como o mito de Kuaray. Trata-se da versão mbya do ciclo tupi-guarani dos gêmeos, versão que nega, entretanto, e com ênfase, a gemelaridade de Kuaray e Jaxy.

$\mathrm{Na}$ verdade, em muitas versōes mbya o tema do adultério não está explícito. Em geral, as narrativas começam a partir do abandono da esposa por Nanderu, divindade celeste, que segue caminho para sua morada no alto. Tomarei aqui, de propósito, um trecho da versáo apapokuva coletada por Nimuendaju (1987), em que o adultério é narrado. Nesta versão, duas divindades estáo presentes no contexto de fundaçáo da vida terrena, Nanderuvuçu e Ñanderu Mbaecuaá, seu companheiro. A esposa de Ñanderuvuçu, irritada porque o marido a teria enviado à roça de milho que acabara de plantar - isto é, náo acreditando que pudesse já trazer milho crescido da mesma, disse a seu marido: 
não tenho o teu filho no ventre, tenho o filho de Mbaecuaá no ventre! [...]. E a mulher de Nanderuvuçu pegou o cesto de carregar e foi na roça. E Ñanderuvuçu pegou os colares de peito, o maracá e também a cruz de madeira; o diadema de penas ele pôs sobre sua cabeça. Ele saiu, rodeou [a casa], foi [embora]. Ele chegou à trilha do Jaguar Eterno, plantou a cruz de madeira, desviou atrás de si [a mulher da sua pista]. (NIMUENDAJU, 1987, p. 143-144)

Nírio, em Araponga, numa ocasião em que narrou esse mito, comentou:

Isso aí que ficou para nós. Qualquer coisinha o homem fica bravo, zangado, já vai embora. Deixa mulher, deixa criança, mulher grávida, qualquer coisinha que não gosta já vai embora.

Mas, se seu comentário indica que o evento mítico teria inaugurado uma conduta masculina, o que vemos na prática é que este é um recurso usado tanto por homens quanto por mulheres no cotidiano das aldeias. Ou seja, unióes e separaçóes de pessoas que "casam" (-menda), se deixam (-eja) e/ou casam com outras (-menda amboae) são processos intimamente ligados aos deslocamentos constantes entre aldeias. O mito traz também, ainda que não desenvolva, um outro aspecto do adultério, que é sua relação direta com o tema da concepçáo e da condiçáo de existência das crianças (recém-nascidas). Nesta mesma versão lemos:

[...] Ñanderu Mbaecuaá foi e provou a mulher. Ele não queria misturar [confundir] o seu filho com [o de] Ñanderuvuçu e Nanderu Mbaecuaá, deu a seu filho um início especial. (NIMUENDAJU, 1987, p. 143, grifo da autora)

Cadogan (1959, p. 43-44) observou entre os Mbya do Guairá a noção de que o adultério durante a gestação poderia levar ao aborto ou morte prematura da criança. Nas aldeias do Rio de Janeiro também ouvi que se o marido ou a esposa cometem adultério durante a gestaçáo, "a criança sente". Vi crianças não receberem seus nomes pessoais durante o ritual nhemongarai por esse motivo, conforme observou Augustinho, pajé responsável pela nomeação na ocasião. Desde o feto, a criança "saberia" e se desagradaria do comportamento de seu pai e/ou mãe, podendo, inclusive, "não querer ficar" na Terra. Nota-se: aqui, como no mito, desagrado e partida estão relacionados. 
A noção de "mistura" no adultério aparece na etnografia de diversos grupos guarani. "Mistura" de sêmen no mito coletado por Nimuendaju (NIMUENDAJU, 1987) ou "cópula dupla" entre os Ava-Katu-Eté (BARTOLOMÉ, 1991, p. 63). Misturar sêmen ou "sobrepor", como lemos na tradução de Cadogan (CADOGAN, 1959, p. 44) parece ter efeitos altamente negativos do ponto de vista da concepção, resultando em fracos ou "maus engendramentos", como no caso da gestação de gêmeos (BARTOLOMÉ, 1991, p. 70-71). ${ }^{5}$

\section{Fuga e silêncio}

O evento do adultério no mito nos abre caminho para dois desenvolvimentos. De um lado, uma abordagem dos deslocamentos - que marcam a ruptura de relacionamentos de casais; de outro lado, um comentário acerca do controle sobre a raiva, -poxy, ou ciúme, akãte’ÿ, e sobre o exercício da sexualidade.

Miguel Chase-Sardi (1992, p. 225), em seu trabalho sobre o que denomina como "direito consuetudinário" dos Ava-Katu Guarani, afirma:

Si la mujer se va con otro hombre, no se molesta a nadie; no se denuncia el hecho al Tekoaruvicha. Lo mismo ocurre con un hombre que abandona a su mujer. Esto es lo que ocurre frecuentemente ahora. ${ }^{6}$

Este seria também um consenso entre homens e mulheres mbya. Não cabe ficar com um parceiro ou parceira sem que se queira fazê-lo, sendo preferível, a certa altura, deixá-lo(a), indo embora do local em que, até então, viviam juntos. Igualmente não se deve apelar a quem supostamente poderia trazer de volta aquele ou aquela que abandonou sua parceira ou parceiro. Mas o que eu gostaria de ressaltar aqui é uma feição particular da fuga tal qual praticada por homens e mulheres mbya: vai-se embora sem falar. É comum que se deixe o parceiro ou parceira sem aviso, em geral, aproveitando-se a oportunidade de uma visita à cidade ou a outra aldeia.

Sem enfrentamentos diretos que poderiam se desdobrar da raiva ou ciúme de quem é deixado(a), nem conversa ou qualquer tipo de negociaçáo, a fuga configura uma espécie padrão de divórcio, de uso rotineiro, mas praticado especialmente quando o rompimento se liga imediatamente à intenção de atualizar um outro envolvimento sexual amoroso com alguém que ali reside e com quem se foge junto. Neste caso, costuma-se sair de modo a não chamar a atenção de corresidentes, em horários de pouco movimento nos pátios, em viagens para outra área. 
Uma questáo que poderíamos colocar de imediato, compreendendo a dimensão de produção/fabricação implicada no parentesco entre povos sul-americanos (VILAÇA, 2002), seria se essas estratégias se mostrariam adequadas à produçáo de aparentamento - ou de humanidade -, considerando a ambivalência na identidade dos recém-nascidos (VILAÇA, 2002). Como ficaria a produção dos vínculos de parentesco na vida diária? $\mathrm{Ou}$, mais diretamente, quais as consequências desse modo de "casar" e "descasar” para a criação de crianças?

De início, a "fuga", que corresponde ao "sair" e "não falar" parece contrastar claramente com as maneiras adequadas de viver entre parentes. A fala é um aspecto central da "estética da produção" (OVERING, 1991) mbya. Falar de modo agradável, aconselhar sem ser excessivo, falar a partir da escuta do que a pessoa veio contar são maneiras fundamentais de produzir uma convivência "boa" - "bonita" -, de que se diz -iko porã, "estar bem" (PISSOLATO, 2007, p. 324-336).

Cabe ainda observar que a "fuga" não está posta como solução para certas situações em particular. É usada tanto entre jovens recém-casados quanto em relaçóes duradouras, com a presença de filhos(as) e/ou netos(as). Nem se liga de modo especial ao que poderíamos reconhecer como um certo estilo relacional no casamento. $\mathrm{Na}$ prática, pode haver uma variação importante desses estilos, seja em termos da divisão do trabalho, da atenção aos filhos ou no tom da convivência. Assim, há casais que se envolvem em cooperação mútua nas atividades diárias e nas decisões negociadas em conversas, até aqueles em que há claro exercício de autoridade do marido e controle sobre as atividades da esposa. Uma tal autoridade pode se manifestar, inclusive, de modo forte, em demandas feitas aos gritos nos pátios, entre outras formas de controle. Entretanto, a despeito das variaçóes, fugir é uma solução que parece produtiva de modo geral. Essa é a pista que eu gostaria de seguir.

\section{Parentesco e emoções}

Tal como apontam muitas etnografias sobre povos amazônicos, a evitação da raiva, do enfurecimento e suas consequências, assim como o controle do ciúme são temas centrais da sociabilidade mbya. Desdobramentos de raiva (-poxy) e ciúme (akâtéy) podem levar os envolvidos a consequências desastrosas envolvendo doença e/ou morte. Assim, pensando nos termos do manejo das emoçóes, é possível supor que a "fuga" possa evitar danos mais graves às pessoas envolvidas. "Não dizer nada" impede enfrentamentos diretos em discussóes ou mesmo agressóes físicas por raiva/enraivecimento (ipoxy). 
Contudo, é certo que não se anula completamente todo e qualquer efeito de raiva ou ciúme que possa vir a se atualizar nesse contexto. A etnografia sobre feitiçaria entre pessoas mbya está repleta de exemplos de agressóes por feitiço feitas por ex-parceiros ou ex-parceiras que foram deixados(as) a certa altura da vida, por quem se tornou mais tarde vítima de sua raiva ou ciúme, que se atualizaram em "doença espiritual”. A propósito, ouvimos dos xamãs que tais doenças seriam enviadas para que se manifestem mais tarde nos que se quer prejudicar.

Por outro lado, cabe considerar de modo mais amplo noções sobre saúde e doença que orientam um conjunto de práticas adotadas pelas pessoas mbya. $\mathrm{O}$ comentário sobre permanecer ou não em determinada aldeia, o interesse em procurar parentes em outras áreas e ir viver perto deles, percepçóes pessoais ou de parentes com capacidades xamânicas reconhecidas, reveladoras de acontecimentos por vir, tudo isso é matéria da produção de saúde. Trata-se de buscar maneiras de "alegrar-se" e "fortalecer-se" para "ficar bem", o que implica muitas vezes em alterar modos de vida e locais de residência e, frequentemente, como temos visto, abandonar relacionamentos e contextos em que se desenvolvem. Ou seja, do ponto de vista de quem "foge", essa saída pode também ser entendida como evitação de uma intensificaçáo de insatisfação, mal-estar ou desânimo que se sente, e de busca por "animar-se" em uma nova situação de vida.

Impressóes e medidas profiláticas ou curativas que venham a ser adotadas com intenção de fazer "alegre" (-vy’a) quem náo esteja se sentindo bem no contexto atual de vida são sempre, e ao final, legítimas. Parentes podem e devem se aconselhar mutuamente, em especial os mais velhos e experientes devem ser consultados. Levam-se até eles sonhos a serem interpretados, dores a serem tratadas, indisposiçôes relacionais etc. Espera-se que tenham algo a dizer, indicaçóes a fazer. Pode-se contar, ainda, com saberes especializados de pessoas mais velhas, xamãs que orientam, tratam, buscam conhecimentos na comunicação com os deuses, ñanderu, que possam indicar um "bom caminho", tape porá. De todo modo, no fim das contas, não cabe opor-se às decisóes pessoais postas em ação, elas seriam já desdobramentos de conhecimentos que a pessoa em questão soube obter. Avaliaçóes sobre "más escolhas" só seriam expressas em situações desastrosas a posteriori, isto é, no caso de "acontecer alguma coisa [altamente danosa]".

Se, como vimos até aqui, é impossível um controle total dos efeitos da raiva e do ciúme - que podem, assim como ocorre na fuga, tornar-se atos sem fala (nesse caso, atos feiticeiros propriamente ditos) -, por outro lado, a fuga garante, em boa medida, a autonomia da pessoa que fez essa escolha. Na prática, podem ocorrer tentativas negociadas de "buscar", por exemplo, uma esposa que fugiu, mobilizando esforços para trazê-la de volta, mas 
não é possível obrigar um homem ou mulher a fazê-lo se a sua escolha foi e continua sendo outra.

De um lado, temos uma ética que aponta para a necessidade de controle sobre o próprio ciúme e a raiva, a qual se evidencia inclusive na reação de alguns homens e mulheres cujos parceiros fugiram e que dizem não sentir raiva ou ciúme por isso. Essa seria a postura mais adequada na avaliação de muitas pessoas, e lembro aqui um comentário de Nírio acerca do ciúme sexual masculino. Ele observou que não caberia aos homens sentir ciúme de suas parceiras já que Jaxy (Lua) todo mês "mexe com as mulheres".

De outro lado, temos a definição de um domínio, ao que parece, inegociável: o do desejo ou do interesse sexual. É possível que haja, como lemos na abertura deste texto, mulheres - homens também - que não se casam com quem querem, mas poderíamos acrescentar: até que decidam pôr fim a essa união.

É importante notar que outras dimensões, que não desenvolvemos aqui, fazem parte do casar, -menda: a cooperaçáo para o sustento e cuidado das crianças; as prestaçóes para algumas categorias de afins; às vezes, a disponibilização de recursos materiais e/ou xamânicos e a organização de atividades produtivas, quando é o caso de casais que reúnem em torno de si um grupo de descendentes. Tais dimensóes são efetivamente experimentadas e podem permanecer como escolhas duradouras feitas pelas pessoas. Mas o que as histórias de fugas e casamentos sucessivos em diferentes aldeias parecem demonstrar é que nenhuma estrutura é capaz de domesticar absolutamente o desejo ou a disposição para o envolvimento sexual. Um homem maduro que visitou por alguns meses a aldeia de Araponga comentou, a propósito do controle que uma mulher teria sobre a sua própria vagina: "sendo dela [da mulher] e ela querendo [envolver-se sexualmente], 'ninguém segura"”. 8

\section{Multilocalidade, parentesco e experiência}

Voltando à questão da produção de parentesco, e mais diretamente àquela da produção e criação de crianças, que, como vimos, se liga, na etnografia de grupos mbya, imediatamente ao tema do adultério (na gravidez), poderíamos nos perguntar: como produzir parentesco dando vazão ao desejo?

Ao fugir, homens e mulheres costumam deixar não apenas o antigo parceiro ou parceira. Como vimos, sendo praticado por jovens ou maduros, em unióes recentes ou há muito constituídas, em numerosos casos o rompimento envolve crianças, que também são deixadas pelo pai ou mãe que vai embora. Na prática, os resultados são variáveis: uma mulher que 
foge pode decidir levar consigo seus filhos menores e deixar os mais velhos; pode deixá-los todos com uma avó que assuma o cuidado por eles; pode ir embora com a expectativa de buscá-los mais tarde. Por sua vez, um homem pode deixar um filho ou filha ainda por nascer, estando grávida sua parceira (como no mito de Kuaray), ou filhos e filhas mais velhos, com os quais poderá um dia tentar se reencontrar. Lembrando o ponto destacado anteriormente acerca do aconselhamento formal para o casamento apenas na maturidade, diríamos que, mesmo que adotada, essa orientação não resolveria efetivamente o problema, já que casais maduros também costumam se abandonar entre si e a seus descendentes. A questáo da produção de parentesco, assim, permanece.

Para respondê-la teríamos que abordar tanto trajetórias pessoais e mudanças de perspectivas que podem variar conforme fases na vida de uma mesma pessoa quanto tendências de personalidade. Seria também necessário acompanharmos a experiência de crianças que são frequentemente adotadas em novos contextos familiares nessas ocasióes, seja sob cuidados de avós ou outros parentes, seja no advento de um novo envolvimento por parte do pai ou máe que teria permanecido junto delas. Não há espaço para fazê-lo neste artigo. Mas quero sugerir que, entre os que "não param" (em nenhum lugar ou relacionamento) e aqueles que estariam vivendo há muitos anos em um mesmo contexto conjugal/familiar, o que parece interessante notar é o campo de possibilidades que se abre à experiência de cada pessoa.

Seguindo a trajetória de muitas mulheres e homens adultos ou velhos, encontramos, em cada uma delas, uma sucessão de lugares e envolvimentos, e a produção de crianças como resultado destes diferentes casamentos. As "paradas" podem ser mais ou menos duradouras; as crianças que resultam dessas unióes podem manter-se juntas, podem ser integradas em casamentos que sucedem o que lhes originou, podem se separar e serem criadas em diferentes contextos.

Se essa dinâmica tende a não fixar a dimensão da produção cotidiana e doméstica do parentesco num único local, também não a anula absolutamente. O processo de produção de parentesco coloca no centro aqui, como em outros contextos sul-americanos, a oferta de alimentos com afeição, a prática de "olhar" as crianças, que envolve o cuidado do sono, medidas profiláticas e curativas com vistas a alegrá-las, erguê-las e fortalecê-las para a vida. Esta dimensão do vivido e construído na prática diária é fundamental quando queremos nos aproximar dos sentidos do parentesco. Mas sugiro que a forma multilocal escolhida pelos grupos mbya possibilita uma profundidade temporal e espacial algo particular na experiência do parentesco pelas pessoas. Ou seja, o universo dos parentes e das possibili- 
dades de produção de parentesco não se limita ao nível local. As feições da "convivialidade" (OVERING; PASSES, 2000) são certamente parâmetros fundamentais para as escolhas de ficar ou deixar uma aldeia; são a matéria do "estar bem", -iko porã, do "ficar alegre", -vy'a, ou não. Elas estão presentes nas narrativas de vida que contam de aldeias onde se viveu bem ou de onde se quis ir embora.

De quem vive junto, num mesmo local, espera-se cooperação, certo grau de partilha e boa disposição, que inclui, entre outras coisas, um "falar bem”. Mas a experiência atual do local onde se vive não afasta, do ponto de vista do parentesco, os parentes que estão longe. Também não transforma os corresidentes em "parentes verdadeiros", como ocorre em diversos contextos amazônicos. Não encontramos aqui, como entre os povos da Guiana (OVERING, 1975; RIVIÈRE, 1984) e outros, como os Piro (GOW, 1991), noções de consubstancialização de afins pela convivência, nem o uso de métodos para cognatizá-los.

Ao que parece, a referência local coloca-se como uma possibilidade no interior de um universo relacional muito mais amplo, estendido pelos inúmeros lugares ou "fogos", tataypy (assentamentos) de que se tem notícia, desde o Paraguai até o Tocantins, onde vivem pessoas relacionadas. Sugiro, assim, que a dimensão da experiência no parentesco mbya tem implicações particulares. Sabendo desde a tenra infância dos muitos lugares onde haveria parentes, ouvindo os relatos de visitantes ou novos moradores que chegam, que passam ou ficam; atualizando em si mesmo intençóes de andar e ver/viver noutros contextos, o parentesco guarda sempre uma abertura às escolhas e capacidades pessoais para atualizar novas relaçóes.

De um lado, o universo multilocal de parentes cria soluçóes viáveis para o tratamento de aspectos "antissociais" da vida local, que se revelam como antipatia, raiva, desânimo, doença; de outro lado, esta multiplicidade abre possibilidades para a atualização daquela instância aparentemente inegociável, que tenho chamado aqui de desejo. A fuga e o início de uma nova relação em outro lugar póem-se sempre como alternativas possíveis.

\section{Agradecimentos}

Agradeço a Luisa Elvira Belaunde, Elsje Lagrou e Marina Vanzolini pela organização do Seminário Foucault na Amazônia? Sexualidades indigenas (PPGAS/UFRJ e PPGSA/UFRJ), realizado em setembro de 2015, no qual este trabalho foi apresentado. Agradeço os comentários e sugestóes de Aparecida Vilaça, Andréa de Oliveira Castro, Rafael Fernandes Mendes Jr, Vanessa Lea e demais participantes do seminário. E, ainda, agradeço e dedico este texto a Ilda da Silva (Yva), companheira de muitas conversas e andanças desde Araponga. 


\section{Notas}

1. Realizei pesquisa de campo nas aldeias mbya guarani de Parati Mirim e Araponga, no sul do estado do Rio de Janeiro, entre os anos 2001 e 2004. $\mathrm{O}$ termo mbya designa um dos três subgrupos guarani que vivem atualmente no Brasil, em todos os estados das regiôes Sul e Sudeste do país, com exceção de Minas Gerais, havendo ainda uma parcela da população no Pará e em Tocantins. Seu maior contingente encontra-se no leste do Paraguai, mas os Mbya estão presentes também nas regiōes de fronteira do Brasil com a Argentina e o Uruguai. Na Enciclopédia dos Povos Indígenas no Brasil, encontramos uma projeção de que a população mbya total estaria atualmente próxima de 27.000 pessoas. No Brasil, conforme dados de 2008, seriam os menos numerosos em comparação com os Guarani Kaiowá (31.000) e Nandeva (13.000), neste período somando cerca de 7.000 pessoas (INSTITUTO SOCIOAMBIENTAL, 2015).

2. Além da etnografia apresentada, que acompanha dois percursos "homossexuais” na região de Dourados, MS, os autores recuperam referências a práticas homossexuais registradas pelos cronistas e viajantes no período colonial e compiladas nos estudos etno-históricos de Luis Mott (1985, 1998 apud CANCELA et al., 2010, p. 213), e também na etnografia de Pierre Clastres sobre os Guayaki (CLASTRES, 1978, 1995). Referências a práticas homossexuais adotadas por homens e mulheres guarani aparecem, também, no Tesoro e Vocabulário do Pe. Ruiz de Montoya (1876) e no estudo detalhado feito por Graciela Chamorro daquilo que essas obras "dizem sobre o corpo" (CHAMORRO, 2010).

3. O envolvimento sexual com brancos é um tema controverso. Apreciado e praticado por diversos homens e mulheres, não deixa de colocar problemas ligados a ñe'ë, princípio anímico de origem celeste da pessoa mbya, assim como relativos ao sangue, tuguy. Algumas pessoas dizem que fazer sexo com jurua "entristece" ñe'ë, enfraquecendo a pessoa. Outras observam o risco de "não aguentar o sangue [de jurua]". Conforme algumas mulheres, só as portadoras de determinados nomes pessoais poderiam ter relações com brancos sem morrer. Numa ocasião, um homem maduro, que diz gostar de fazer sexo com brancas, comentou que, a seu ver, "hoje o sangue é tudo igual" devido às mudanças na alimentação das pessoas mbya, de modo que não haveria problemas no sexo com brancos. Não desenvolverei tais questôes, mas chamo a atenção para uma distinção importante entre o "casar com jurua" e o "casar nas aldeias". O casamento com jurua é duradouro, da perspectiva das pessoas mbya, retirando a mulher ou homem envolvido do circuito da reciprocidade mbya (PISSOLATO, 2012).

4. O processo chamado -jepota não ocorre apenas com rapazes e moças na 
puberdade, sendo um risco importante na couvade e um acontecimento algo frequente no contexto da morte. Sem discutir sua complexidade (ver análise de MENDES JR, 2009, p. 107-114), interessa-me enfatizar aqui um modo típico de transformação animal por meio da sedução sexual, o que Schaden (1962, p. 89-90) denominou "encantamento sexual”. Um rapaz ou moça depara-se com alguém na mata, que vê como possível parceira ou parceiro muito atraente. $\mathrm{O}$ envolvimento sexual nesse contexto dá início ao processo de transformação - na espécie do animal daquele(a) que é visto(a) ali como gente - e costuma completar-se na visita à sua aldeia e no consumo de comida lá ofertada.

5. Observo aqui o contraste com teorias amazônicas em que o acúmulo de sêmen é condição para a produção da criança em gestaçáo, sendo comum a participação de diversos parceiros sexuais da mulher neste processo. Sobre a concepção de gêmeos, Cadogan a associa a Mba'e Poxy (CADOGAN, 1959, p. 119), que considera como "ser" produtor de enfurecimento (-poxy), a qualidade antissocial por excelência; daí a presença de gêmeos ser considerada altamente nefasta nas aldeias mbya.

6. Se a mulher vai embora com outro homem, isso não molesta ninguém; o fato não é relatado ao Tekoaruvicha (chefe local). O mesmo ocorre com um homem que abandona sua esposa. Isso é algo que acontece com frequência atualmente.

7. Jaxy copula a cada mês com as mulheres antes da menstruação, o que não é visível, contudo, para elas ou quem quer que seja. É também quem deflora as meninas, "forçando-as", como disse Nírio, para que cresçam logo, pois quer copular com elas.

8. No limite, não se "segura" o sexo nem mesmo nos casos em que há um grau importante de consenso quanto a prejuízos que poderiam trazer, como no relacionamento com jurua. Neste caso, muitas mães aconselham suas filhas a não se envolverem com brancos, e, por sua vez, muitas moças o fazem, algumas delas sustentando o argumento de que brancos tendem a ser mais "carinhosos" no sexo.

\section{Referências Bibliográficas}

CADOGAN, León. Ayvu Rapyta: textos míticos de los Mbyá-Guaraní del Guairá. São Paulo: USP/Edição Faculdade de Filosofia, Ciências e Letras, 1959.

BARTOLOMÉ, Miguel A. Chamanismo y religion entre los Ava-Katu-Ete. Assunción: Centro de Estudos Antropológicos. (Biblioteca Paraguaya de Antropologia 11), 1991.

BELAUNDE, Luisa E. Resguardo e sexualidade(s): uma antropologia simétrica das sexualidades amazônicas em transformação. Cadernos de campo, 2016. 
CANCELA, Cristina D.; SILVEIRA, Flavio L. A.; MACHADO, Almires. Caminhos de uma pesquisa acerca da sexualidade em aldeias indígenas no Mato Grosso do Sul. Revista de Antropologia, v. 53, n.1, p. 200-235. 2010.

CHAMORRO, Graciela. Decir el cuerpo: historia y etnografia del cuerpo en los pueblos Guaraní. Asunción: Tiempo de Historia, Fondec, 2010.

CHASE-SARDI, Miguel. El precio de la sangre: Tugüy Neë Repy. Estudio de la cultura y el control social entre los Avá- Guaraní. Asunción: Centro de Estudos Antropológicos. (Biblioteca Paraguaya de Antropología 16), 1991.

CLASTRES, Pierre. A sociedade contra o Estado. Rio de Janeiro: Francisco Alves, 1978.

Crônica dos Índios Guayaki: o que sabem os Aché, caçadores nômades do Paraguai. Rio de Janeiro: Editora 34, [1972]1995.

FOUCAULT, Michel. História da sexualidade 1: a vontade de saber. $3^{\text {a }}$ ed. Rio de Janeiro:

Graal, 1980.

GOW, Peter. Of Mixed Blood: kinship and history in Peruvian Amazonia. Oxford: Clarendon Press, 1991.

GREGOR, Thomas. Anxious Pleasures. Chicago, London: The University of Chicago Press, 1985.

INSTITUTO SOCIOAMBIENTAL. Enciclopédia dos povos indígenas no Brasil. Disponível em: <http://www.socioambiental.org.br>. Acesso em: 24 de abril de 2015.

LEA, Vanessa R. Foucault (parcialmente) vindicado no Brasil Central: sexualidade como um dos fundamentos da vida. Cadernos de campo, 2016.

MCCALLUM, Cecilia. Nota sobre as categorias "gênero" e "sexualidade" e os povos indígenas. Cadernos Pagu, n. 41, p. 53-61. 2013.

MENDES JR., Rafael F. Os animais são muito mais que algo somente bom para comer. Dissertação de mestrado em Antropologia, Universidade Federal Fluminense, Niterói, 2009.

MONTOYA, Ruiz de. Vocabulario y tesoro de la lengua Guaraní, o más bien Tupi. Viena/Paris: Editora Do Visconde de Porto Seguro, Faesy y Frick/Maisonneuve y Cia., 1876.

NIMUENDAJU, Curt U. As lendas de criação e destruição do mundo como fundamentos da religião dos Apapocúva-Guarani. São Paulo: HUCITEC; Editora da Universidade de São Paulo, 1987 [1914].

OVERING, Joanna. The Piaroa: a people of the Orinoco Basin. Oxford: Clarendon Press, 1975.

- A estética da produção: o senso de comunidade entre os Cubeo e os Piaroa. Revista de Antropologia, v. 34, p.7-33. 1991.

OVERING, Joanna; PASSES, Alan. (Eds.). The Anthropology of Love and Anger: the aestheics of conviviality in native Amazonia. London: Routledge, 2000.

PISSOLATO, Elizabeth. A duração da pessoa: mobilidade, parentesco e xama- 
nismo Mbya (Guarani). São Paulo, Rio de Janeiro: Editora da Unesp, NuTI Museu Nacional, 2007.

Gênero, casamento e trocas com brancos. In: SACCHI; GRAMKOW

(Org.). Gêneros e povos indígenas. Rio de Janeiro, Brasília: Museu do Índio, GIZ/FUNAI, 2012.

RIVIÈRE, Peter. Individual and society in Guiana: a comparative study of Amerindian social organization. Cambridge: University Press, 1984.

SCHADEN, Egon. Aspectos fundamentais da cultura Guarani. São Paulo: EPU/ Edusp, 1962.

VILAÇA, Aparecida. Making Kin out of Others in Amazonia. Journal of Anthropological Institute, n. 8, v.2, p. 347-365. 2002.

\section{autora Elizabeth Pissolato}

Professora de Antropologia no Programa de Pós-Graduação em Ciências Sociais e no Departamento de Ciências Sociais da Universidade Federal de Juiz de Fora/UFJF.

Recebido em 10/12/2015

Aceito para publicação em 10/12/2015 